\title{
Cultural Factors in International Chinese Teaching Take HSK Teaching as an Example
}

\author{
Siqi Yun ${ }^{1}$

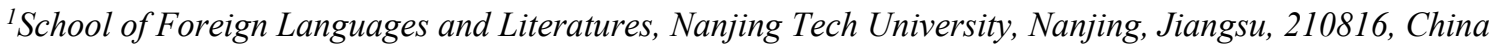 \\ Corresponding author's e-mail: ShiLiShuang@cas-harbour.org
}

\begin{abstract}
With the continuous advancement of globalization, the demand for language exchanges between countries has increased. Cultural factors play an important role in language learning, in the process of teaching Chinese as a foreign language, people are paying more and more attention to Chinese learners' understanding of Chinese culture. This article mainly uses investigation to collect relevant information, the content of the investigation included literature related to cultural education, HSK, and international Chinese education. The subjects of the questionnaire included 50 Chinese learners from different countries around the author. $82 \%$ of learners believe that cultural factors are necessary in Chinese language learning, $10 \%$ believe that it is partially necessary, and up to $84 \%$ of learners are more willing to understand Chinese social culture. The results of the study found that the combination of Chinese cultural factors and language teaching has a positive impact on Chinese international teaching, but there are still problems in the structure of cultural education. Besides, the addition of cultural factors has also increased the difficulty of teaching Chinese as a foreign language and the pressure of Chinese learners. Further research is needed on how to enable Chinese learners of different levels to easily and effectively understand the diverse Chinese culture.
\end{abstract}

Keywords: Cultural factors, international Chinese education, HSK, insufficiency of existing international Chinese teaching, teaching Chinese as a foreign language (TCFL)

\section{INTRODUCTION}

With China's economic development, economic exchanges, academic exchanges, and cultural exchanges between countries and China are frequent. Foreigners who come to China to study and work are also on the rise. Therefore, language learning on paper can no longer satisfy Chinese learners' demand. They need the ability to enable them to communicate with Chinese speakers without barriers and integrate into the Chinese social environment. HSK is the threshold for foreigners to study, live and work in China. More and more Chinese learners are beginning to devote themselves to HSK study and examination. China National Chinese Language International Promotion Leading Group Office launched a new version of HSK in 2009, emphasizing the comprehensive improvement of listening, speaking, reading and writing skills in the process of teaching Chinese as a foreign language, making the test more reliable and valid. Compared with the old HSK, in the new HSK test, there are many questions related to Chinese culture. The attention to the new culture-related test questions aroused the author's thinking, and based on this discovery, the author explored the influence of cultural factors on Chinese international teaching, whether there are any problems in the current cultural teaching in teaching Chinese as a foreign language, and ideas for solving these problems. Through literature review and a survey, the purpose of this article is to explore the influence, current situation and suggestions of cultural factors in teaching Chinese as a foreign language.

\section{ANALYSIS ON THE CULTURAL FACTORS OF HSK}

\subsection{A brief introduction about HSK}

HSK is the abbreviation of Chinese "hànyǔ shuǐpíng kăoshi” which means "Chinese proficiency test”. HSK was officially promoted in China in 1990, and began to be promoted overseas in 1991. It is a national standardized test set up to test the Chinese proficiency of non-native Chinese speakers such as foreigners, overseas Chinese and ethnic minorities in China. There are various types of HSK, including youth HSK (YCT), business HSK, travel HSK, and secretarial HSK to meet the needs of different 
candidates. On the exam setting, HSK focuses on examining students' Chinese communicative competence and has separate written and oral exams. The written test includes one to six levels, the oral test includes elementary, intermediate, and advanced. Changlai Chen (2005) mentioned: "As a national standardized test, the HSK test has reached a high level of scientific. It has realized the standardization of test preparation, test administration, scoring and score interpretation, as well as test question prediction, statistical equivalence, test registration, and score printing, certificate printing, etc."[1] HSK has now become the threshold for non-native Chinese speakers to work, study and live in China.

\subsection{Cultural factors reflected in HSK}

Regarding cultural factors, it actually contains a very broad concept. Li Quan (2004) proposed that cultural factors refer to those closely related to the understanding and use of the target language, which are mainly implicit in the structure and expression system of the target language, reflecting the specific cultural connotations of the target language nation's food, clothing, shelter, ethics, lifestyle, way of thinking, values, customs, aesthetic tastes, right and wrong orientations, etc.

From the perspective of the content of the test, the HSK has added factors related to Chinese culture in both the teaching process and the examination. In the "find out the wrong sentence" reminder in the reading part of the exam, the stem of the question will also involve Chinese cultural content, such as "Ancient Chinese blue and white porcelain, paintings and decorations are delicate and elegant, and there are many types of patterns and knowledge. Each period has distinctive characteristics of the times." Another example is the fill-in-the-blank question: "Autumn Tiger" is a common name among Chinese folks for the short-term weather that reappears after the fall. It usually occurs at the turn of August and September, about one to two weeks. When this kind of weather appears, it is called "Autumn Tiger" because it is hot, sunny and uncomfortably hot for people. " (HSK6 Exam Paper April 2013 H61329 Reading) To a certain extent, these knowledges can bring some advantages to Chinese learners who will come to live and work in China.

\subsection{The influence of cultural factors on teaching Chinese as a foreign language}

Cultural factors play an important role in language learning. The teaching mode that combines cultural education and language education has become a consensus, like Jie Fang (2009) mentioned: "Language and culture are inextricably linked, so when we learn the language of a nation, we must not only learn the pronunciation of this language, Vocabulary and grammar, we should also understand the unique culture of this nation, understand the profound cultural factors contained in the target language, and understand how members of this nation use their language to reflect their nation and social culture."[2] The popularization of Chinese culture has some positive impacts on international Chinese teaching to a certain extent.

First, the setting of cultural content can arouse learners' interest in learning, because cultural content is more vivid and interesting than boring and theoretical language knowledge. When students are tired of language learning, they can change their thinking and relax by reading these contents. Second, cultural materials about festivals and customs will help learners follow the customs after they come to live and work in China. They can send appropriate blessings during traditional Chinese festivals; it also allows them to enjoy the Chinese holiday celebration. Third, learning Chinese culture can help Chinese learners better master the ways and skills of communicating with Chinese people. Cultural education is not only festivals, customs, etiquette, literature and art, classic works, but also includes a country's world outlook, outlook on life, and values, as well as the source of a nation's behavior and style. Bisong Lv (1989) pointed out: the cultural traditions, social customs, mental states, and ways of thinking of each ethnic group have their own characteristics. These characteristics must be reflected in the ethnic language and others.[3] If foreigners learn Chinese, if they do not learn these cultural factors at the same time, they cannot understand correctly. If you use Chinese, you will encounter obstacles in communicating with Chinese people and even make jokes. Those foreign bloggers who have attracted a large number of fans by relying on their authentic Chinese all have a deep understanding of a wide range of Chinese culture, and they have even more knowledge of Chinese culture than some Chinese natives. Only by mastering the Chinese people's way of thinking and language habits can we use the same way to express authentic Chinese and can understand certain cultural differences in the process of interacting with Chinese people to avoid misunderstandings.

\subsection{The influence of cultural factors on Chinese learning}

Not only scholars support the combination of cultural education and language education, many students also agree with this teaching method. The author conducted a questionnaire survey on 50 Chinese language learners. The purpose of this questionnaire survey is to understand Chinese learners' views on cultural factors. The questionnaire design is as shown below. 
1. Your nationality?

\begin{tabular}{|c|c|c|c|}
\hline \multicolumn{4}{|c|}{ 2. How old are you now? } \\
\hline Under $20 \square$ & 20-30 ㅁ & $30-40 \square$ & Over $50 \square$ \\
\hline \multicolumn{4}{|c|}{ 3. How long have you studied Chinese? } \\
\hline Less than one year $\square$ & $\checkmark \quad 1-2$ years $\square$ & $2-3$ years $\square$ & More than 3 years $\square$ \\
\hline \multicolumn{4}{|c|}{ 4. Is there any content about Chinese culture in the process of learning Chinese?? } \\
\hline There are many $\square$ & Yes but not many $\square$ & No $\square$ & Did not notice $\square$ \\
\hline
\end{tabular}

5. Do you like the content about Chinese culture?

\begin{tabular}{|c|c|c|c|c|}
\hline Like very much $\square$ & General $\square$ & Partly like $\square$ & \multicolumn{2}{|c|}{ Dislike $\square$ Why? } \\
\hline \multicolumn{5}{|c|}{$\begin{array}{l}\text { 6. Do you think it is necessary to study the corresponding national culture in the } \\
\text { process of learning a foreign language? }\end{array}$} \\
\hline $\begin{array}{l}\text { Necessary } \square \\
\text { Why? }\end{array}$ & Partly ne & sary $\square$ & Doesn't matter $\square$ & No need $\square$ \\
\hline
\end{tabular}

7. Do you want to see a display of traditional Chinese art in class?

\begin{tabular}{ll|l|l} 
Yes $\square$ & Yes but not too often $\square$ & Doesn't matter $\square$ & No $\square$ Why?
\end{tabular}

8. What aspects of Chinese culture do you want to know more?

\begin{tabular}{l|l|l|l} 
Traditional Arts $\square$ & Society $\square$ & Literature
\end{tabular}$\quad$ Other $\square$ For example

Figure 1 Questionnaire on the influence of cultural factors on Chinese learning

The form of the questionnaire is based on multiple choice questions and contains four options. The questionnaire is distributed online and is distributed to foreigners who are studying Chinese (mainly foreign students in China, but also those who have already participated in work and those who are studying Chinese in their own country). A total of 50 questionnaires were sent out and 50 were returned. The main survey results are as follows:

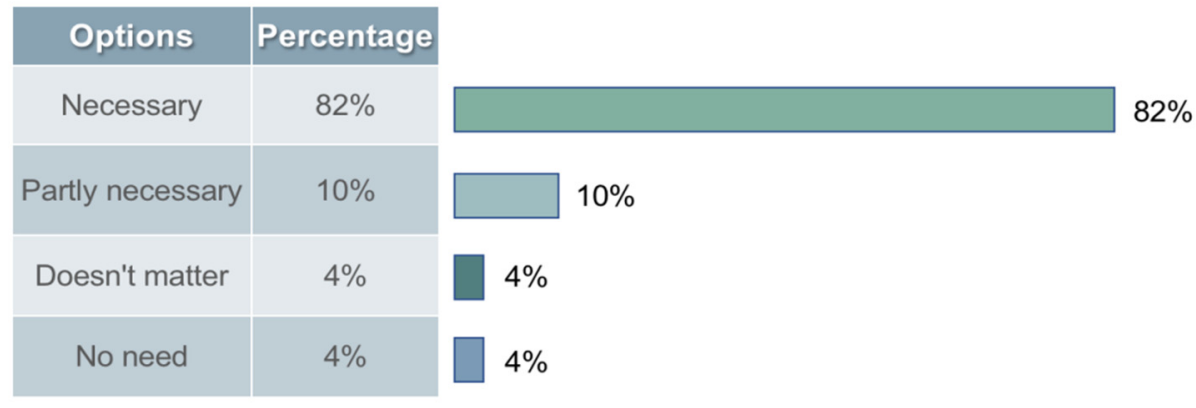

Views on the importance of cultural factors

Figure 2 Views on the importance of cultural factors 


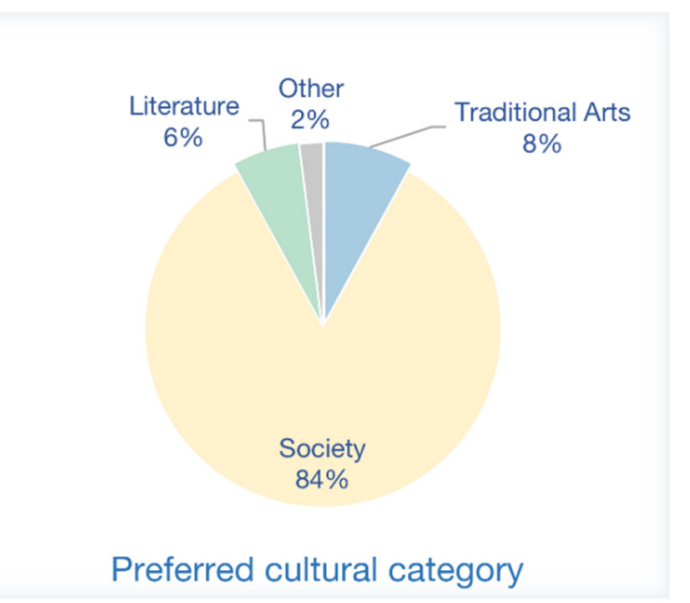

Figure 3 Students' preferred cultural category

Under the question "Do you think it is necessary to study the corresponding national culture in the process of learning a foreign language?", 41 people chose "Necessary", 5 people chose "Partly necessary", and 2 people chose "Doesn't matter". There are 2 people who are" No need". The data show that the majority of people who think it is necessary to add corresponding Chinese cultural teaching to language learning. There are two main reasons why most people think it is necessary, one is "interest" and the other is "conducive to learning a foreign language and living in a foreign country." Among them, $77 \%$ choose the latter. In addition, the author found that most of the 41 people who choose "Necessary" performance better in Chinese learning. Therefore, it can be said that cultural factors can indeed produce certain benefits to Chinese learning. Eighty-four percent of people want to learn more about Chinese social culture, which to a certain extent shows that learners need to be close to the cultural factors of social communication rather than art.

The results of the questionnaire show that most Chinese learners tend to understand the relevant culture in the process of learning Chinese, and cultural factors are an indispensable part of teaching Chinese as a foreign language. It also caters to the previous point of view. At the same time, Chinese learners want to know more about Chinese social culture and have little interest in traditional arts and literature. It also provides a reference for the setting of cultural content in Chinese teaching in the future, which is to increase the proportion of social cultural content and reduce the proportion of traditional art and literature-related content, which can maximize the learning interest of Chinese learners.

\section{CURRENT DEFICIENCIES OF CULTURAL EDUCATION IN CHINESE INTERNATIONAL EDUCATION}

In generally, the current teaching of Chinese as a foreign language attaches great importance to the addition of cultural factors, but there are two main problems: One is that the cultural content and actual Chinese communication in some textbooks will be separated from each other, the other is that cultural factors are not balanced in the classroom and mainly focuses on traditional art.

Jiazhen Xu (2000) suggested that in language teaching, we should organically, appropriately and purposefully add cultural teaching content. It seems that we have not been able to find the most helpful and targeted cultural entry point for improving students' language communication skills. [4] At present, the compilation of Chinese textbooks in China is becoming more and more perfect. As Yuchuan Liu (2017) said, there are currently thousands of teaching materials for Chinese as a foreign language, and more and more attention is paid to the cultivation of learners' communicative competence, the need for cultural and nationalization, etc. [5] Some textbooks have been able to integrate cultural points into the texts, such as "HSK Standard Course", "Quick Spoken Chinese · Intermediate", etc. However, there are still many textbooks that cannot achieve this effect. The second chapter of the textbook "Cultural China" is the subject of Chinese etiquette and customs. The text roughly introduces China's representative etiquette and customs culture, but the content is very abstract, making it difficult for most Chinese learners to understand and use in communication. It caused the textbook to lose its practicality and operability.

The emphasis of cultural teaching in Confucius Institutes too inclined to Chinese artistic skills. As a student of Chinese International Education, there is a requirement that it is best to master a traditional Chinese art skill, which can be traditional Chinese musical instruments, traditional Chinese dance, traditional Chinese calligraphy, traditional Chinese painting, and the student must have at least one skill so that they can pass the interview to be an international Chinese teacher. Yongfang Zhang (2019) analyzed the "Chinese Volunteer Handbook for International Chinese Language Teachers" and found that more than one-third of it talked about Chinese talents [6]. Jianming Lu and Zhen Ma (2016) also proposed that Confucius Institutes and Confucius Classrooms generally engage in cultural and technological activities.[7] It can be seen that the current international education of Chinese has made great efforts to popularize Chinese traditional arts. Such a requirement is undoubtedly a kind of pressure for international Chinese teachers, especially for those who have no artistic expertise before learning this major. The reason is that the mastering of these traditional art skills requires a lot of time and energy, which will take up the study time or lesson preparation time of the main course. Take English education as an example. Nowadays, in developed cities in China, most of the students are exposed to English from kindergarten to university. During this long English learning process, students are not required to understand British traditional musical instruments and dance culture. 
But this may not prevent them from integrating into British social life in the future. A large number of Chinese students studying in the UK can prove that they do not understand British traditional arts and culture, but they have not affected their daily communication and life.

There is no doubt that traditional art is also an important part of culture. However, the result of the survey mentioned above proves that traditional art is not necessary in teaching Chinese as a foreign language. Because only $8 \%$ of people tend to understand this content, most people are not interested, so it is actually thankless to always set up courses and activities related to traditional Chinese art. Special art classes can be used to let interested students learn, but traditional art and culture need not be brought into general language teaching classes too much. In addition to the factor of students' interests, there are other drawbacks. The first problem is that this kind of culture places too much emphasis on artistry and is not commonly used in actual daily Chinese applications. The cultural teaching of traditional art can be appropriately arranged in the process of international Chinese teaching to adjust the boring classroom but it should not take too much time, otherwise it will reduce the classroom effectiveness of language teaching. Besides, if traditional cultural displays with similar forms always appear in the classroom, it can easily cause resistance from learners who are not interested in it. The second problem is that and it does not allow Chinese learners to master more authentic Chinese expressions, nor can they get in touch with the core of Chinese culture. Obviously, this does not take into account the needs of students to learn and use Chinese because the focus of international Chinese teaching lies in the ability to use Chinese in daily lives but the content of traditional art is only involved in specific occasions.

\section{SUGGESTIONS}

First of all, Chinese international educators need to find a better way to naturally integrate Chinese culture into language teaching. Combine the originally independent texts with the expanded content of cultural knowledge. For example, teachers can let Chinese learners practice dialogue and writing based on the cultural materials, and require them to use the grammar taught in the text. Second, in view of the fact that theoretical and abstract ideas and culture are too difficult for learners of lower Chinese proficiency to understand, different types of cultural teaching should be classified according to different Chinese proficiency. For example, for HSK elementary Chinese learners, teachers can only teach art and culture, festival culture and other wellunderstood content, while for HSK intermediate learners, there can be content about history, culture, behavior and habits. For HSK advanced level, the learners can be taught about the related thinking models, awareness and culture aspects and so on. Finally, the current cultural and educational concepts of international Chinese educators should be changed, and it should no longer continue to force teachers of Chinese as a foreign language to master a traditional Chinese artistic skill.

For international Chinese teachers, mastering a traditional Chinese artistic skill does not mean the ability of playing a piece of music with a national instrument, performing the traditional dance, or cutting a window grille, because teachers cannot show the same talents to students every time. It requires international Chinese teachers to always master new tunes, new dance moves and new paper-cutting methods. It will consume a lot of energy for international Chinese teachers in the spare time of heavy work, and it will be a burden for those teachers who have no interest in learning these skills purely for work. Instead, they should be allowed to understand all aspects of Chinese culture in a broad and as detailed manner as possible in order to use it in future teaching.

\section{CONCLUSION}

Based on the research findings of this article, there is no doubt that correct and appropriate cultural education will have a positive impact on Chinese international education, it can inspire Chinese learners, help them understand Chinese culture, assist them in using more authentic Chinese. However, in the process of research, it is found that there are problems with the existing teaching model of Chinese culture as a foreign language: the addition of cultural materials in the textbooks, the integration of language teaching in Chinese, and the current focus of cultural education in Chinese as a foreign language is that there is too much emphasis on festivals and art. In response to the existing problems, the author puts forward some ideas to solve these shortcomings, which including changing the way in which cultural factors appear in textbooks, adjusting the focus of cultural education in teaching Chinese as a foreign language, and providing different types and difficulty of cultural teaching for Chinese learners of different levels. For how to implement the above measures, further research is needed.

\section{ACKNOWLEDGMENT}

In the study process of the scientific research project course "Globalization, Education and Public Policy", I learned a lot of previously unfamiliar knowledge and generated a lot of related thinking, which has gained a lot. This course brought inspiration to the writing of this thesis. Thanks to the teaching assistant for the revision of the thesis outline and the instructor's revision feedback. Thanks to everyone who helped me in the process of writing the paper, this writing experience enriched my English thesis writing experience, also increased my 
understanding and thoughts on the topic. It has accumulated valuable experience for my future study.

\section{REFERENCES}

[1] C. Chen. Introduction to Teaching Chinese as a Foreign Language, Fudan University press, 2005, 261.

[2] J. Fang. The Importance of Cultural Factors in Second Language Teaching-_- Taking the translation of English and Chinese proverbs as an example, Humanities Series (00), 2009, 187.

[3] B. Lv. The Development of Teaching Chinese as a Foreign Language in China, Chinese Teaching in the World, 1989 (4), 193-202.

[4] J. Xu. The problem of combining language teaching and cultural teaching in basic language courses, Teaching Chinese in the world, 2000 (3), 75-82.

[5] Y. Liu. Combination of Test and Teaching - Taking "HSK Standard Course 1" as an example to discuss the development trend of teaching Chinese as a foreign language, Higher Education Journal, 2017 (18), 103.

[6] Y. Zhang. Chinese Culture Teaching in a NonChinese Environment - - Taking the US Elementary and Intermediate Chinese Teaching Model as an Example, International Chinese Teaching Research, 2019 (02), 57.

[7] J. Lu \& Z. Ma. The quality and basic skills that a Chinese teacher should have, Foreign Language Teaching and Researching Press, 2016, 81-84. 